\title{
PENGEMBANGAN PEDOMAN RUANG RAMAH ANAK BERBASIS KEARIFAN LOKAL UNTUK FASILITAS PENDIDIKAN USIA DINI
}

\author{
Hajar Pamadhi, Dwi Retno Ambarwati, Eni Puji Astuti \\ Jurusan Pendidikan Seni Rupa, FBS, Universitas Negeri Yogyakarta \\ E-mail: hpamadhi@yahoo.com
}

\begin{abstract}
Abstrak
Buku Pedoman Ruang Ramah Anak Berbasis Kearifan Lokal tahun kedua difokuskan pada penyempurnaan isi, tata tulis dan kelengkapan gambar agar terbaca dengan jelas oleh pengguna. Langkah penyempurnaan dengan jalan (1) melengkapi ilustrasi sesuai dengan poetunjuk serta menyesuaikan dengan bahasa formal. (2) memvalidasi dengan pakar pendidikan anak usia dini, Guru pendidikan anak nusia dini serta pemangku kepentingan dari subbag sarana-prasarana Dinas Pendidikan, Pemuda dan Olah Raga. (3) Fokus Group Discussion dan Seminar. Hasil perbaikan digunakan untuk menyempurnakan buku panduan yang dimaksud.
\end{abstract}

Kata kunci: pedoman ruang ramah anak, berbasis kearifan lokal.

\section{THE DEVELOPMENT OF THE HANDBOOK FOR LOCAL WISDOM- BASED KID-FRIENDLY ROOMS FOR THE FACILITY FOR PRE-SCHOOL EDUCATION}

\begin{abstract}
The Handbook for Kid-Friendly Rooms Based on Local Wisdom for the Facility for Pre-School Education in the second year focuses on the revision in terms of content, writing system, and pictures so that users can have a clear comprehension. The completing action was conducted by (1) completing the illustration and adjusting the explanation to the formal language, and (2) validating the completion with the experts of pre-school eduation, the teachers, and the stakeholders from the government officials of Facilities and Infrastructure in the Agency of Education, Youth, and Sport Affairs. Focus Group Discussion and seminar were also conducted to perfect the handbook.
\end{abstract}

Keywords: handbook for kid-friendly rooms, local wisdom-based 


\section{PENDAHULUAN}

Sampai saat ini Pemeintah Republik Indonesia, dalam hal ini Departemen Pendidikan dan Kebudayaan, khususnya Direktorat Pendidikan Luar Sekolah dan Pendidikan Anak Usia Dini belum mengeluarkan pedoman penyelenggaraan ruang ramah anak. Pedoman yang ada berupa buku standar pelayanan minimal yang bersifat umum. Berangkat dari kebutuhan tersebut dan perihal pendidikan untuk anak perlu disusun buku pedoman tentang ruang anak. Ruang anak yang dimaksudkan adalah ruang yang nyaman dan membantu perkembangan anak, seperti perkembangan daya pikir, rasa maupun keterampilan khasnya.

Penyusunan Buku Pedoman Ruang Ramah Anak untuk Lembaga Pendidikan Anak Usia Dini berbasis kearifan lokal melalui penelitian tentang: kebutuhan dasar untuk bermain, belajar dan bersosial. Ruang ramah anak diajukan untuk menaungi penelitan terhadap kebutuhan pengembangan ini untuk anak usia dini, sebab pada usia dini terdapat kecenderungan lebih dekat nuansa bahasa ibu. Termasuk di dalamnya adalah bahasa ibu, tradisi keluarga dan lingkungan sekitar yang terakumulasi dengan fasilitas fisik. Perhatian terhadap kebutuhan ruang bagi anak usia dini (AUD) mempunyai posisi strategis dalam pembangunan kognisi, rasa maupun keterampilan. Konteks suasana anak, komunitas anak mempunyai posisi strategis yaitu sebagai embrio komunitas baru yang tumbuhkembang dengan penyediaan fsilitas secara optimal namun dalam lingkungan wajar didukung oleh keluarga, sekolah, dan masyarakat (UU No.20 Tahun 2003).

UNICEF menyusun pedoman sekolah Ramah Anak (Child Friendly School) yang diterapkan di semua negara di dunia. Pedoman ini berisi: pertimbangan perancangan ruang dan fasilitas pendidikan ramah anak, pemilihan lokasi sekolah, desain, konstruksi, pengelolaan pendidikan yang ramah anak, dan faktor-faktor penting memperbaiki dan meningkatkan kualitas sekolah agar menjadi ramah anak. Tujuan utama child-friendly school adalah menarik siswa senang bersekolah (increase access), meningkatkan pencapaian hasil belajar, menyediakan lingkungan aman, menyenangkan, nyaman bagi anak, lingkungan yang memudahkan anak mengakses segala fasilitas belajar (termasuk bagi yang memiliki kekurangan fisik/difabel), membangun keterikatan dengan sekolah (institutional ethos), melibatkan orang tua dan 
masyarakat dalam pendidikan anak (support and participation), menciptakan hubungan harmonis antara sekolah dan masyarakat. Persoalan ini belum merujuk kepada konteks Yogyakarta sebagai kota pendidikan dan kebudayaan. Pedoman pengembangan ruang ramah anak ini didasarkan pada nilai-nilai kearifan lokal Yogyakarta, sehingga tingkat kesesuaian lebih dekat.

Seiring dengan prinsip pendidikan tumbuh kembang anak tersebut diperlukan persyaratan ruang dan sarana pendidikan yang ramah anak pada tingkat pra sekolah (PAUD). Ketersediaan fasilitas dan sarana pendidikan tidak sesuai dengan karakteristik anak, misalnya: handel pintu ruang kelas atau ruang bermain masih tinggi, toilet tidak bersih, lokasi bermain outdoor di paving, sehingga anak tidak bisa mengenal alam sekitar dan tidak dapat bermain dengan nyaman karena licin. (Suara merdeka, 12 april 2011). Hasil penelitian menunjukkan bahwa penerapan persyaratan ruang ramah anak belum sesuai standar, misal: fasilitas playground tidak aman, bentuk perabot tidak sesuai dengan karakteristik motorik anak, dan sebagainya (Dwi Retno, 2012, di PAUD di Kecamatan Pleret Kabupaten Bantul). Berangkat dari permasalahan di atas, perlu disusun Pedoman Pengembangan Ruang Ramah Anak Berbasis Kerarifan Lokal sebagai pedoman penyelenggaraan ruang beserta fasilitas pendidikan yang ramah anak.

Untuk menyusun pedoman tersebut penelitian ini mengacu deklarasi $A$ World Fit For Children diterjemahkan menjadi Program Nasional Bagi Anak Indonesia (PNBAI) 2015 dan dijadikan acuan program Kementerian Pemberdayaan dan perlindungan Anak (KPPA) sampai tahun 2015: mencakup 4 (empat) bidang pokok: (1) promosi hidup sehat; (2) penyediaan pendidikan berkualitas; (3) perlindungan terhadap perlakuan salah; eksploitasi dan kekerasan; serta, (4) memerangi HIV/AIDS.

\section{Kota Layak anak menuju Sekolah Layak Anak}

Kota Layak Anak (KLA) adalah kota yang menjamin hak setiap anak sebagai warga kota untuk melindungi dan memfasilitasi anak tumbuh layak. Perihal hak-hak anak oleh Indonesia dinyatakan secara jelas dalam Undang-Undang Dasar tahun 1945 pasal 28 b ayat 2: "Setiap anak berhak atas kelangsungan hidup, tumbuh, dan berkembang serta berhak atas perlindungan dari kekerasan dan diskriminasi." Sebagai 
tindak lanjut ditetapkan melalui Undang-Undang Nomor 23 Tahun 2002 berisi tentang Perlindungan Anak dan diperkuat dengan Peraturan Menteri Pemberdayaan Perempuan dan Perlindungan Anak Republik Indonesia Nomor 13 Tahun 2010 tentang Pedoman dalam Peraturan disebutkan bahwa anak merupakan generasi penerus dan potensi bangsa, untuk itu perlu dilindungi dan dipenuhi hak-haknya agar dapat hidup, tumbuh dan berkembang dalam lingkungan yang layak. Lingkungan layak anak masuk dalam konstelasi Kota Layak Anak, penelitian Kota Layak Anak di Kota Yogyakarta, merekomendasikan:

“ a. Lingkungan dan nilai-nilai luhur pada anak, akan diungkap norma, tata pergaulan sosial serta adat yang masih relevan untuk pendidikan karakter anak

b. Hak sipil anak, adalah hak mengutarakan pendapat dan berkembang sesuai dengan minat serta kegemaran anak.

c. Anak berkebutuhan khusus, berupa fasilitas tumbuhkembang anak sesuai dengan tingkat kebutuhan serta kondisi anak.

d. Masalah sosial anak, berupa permasalahan pribadi serta permasalahan umum yang yang diprediksi akan mengganggu perkembangan jiwa, pendidikan serta rasa sosial anak.” (Hajar Pamadhi, 2011).

Dukungan terhadap prinsip kota layak anak diantaranya dengan sekolah layak anak dan ruang belajar ramah anak. Ruang ramah anak merupakan ruang kelas dan lingkungan sekolah yang menarik dan nyaman. Furlong (2007:2) menjelaskan: “(a) anak-anak perlu aman dalam melakukan kegiatan atau aktifitas; (b) lingkungan sekitar harus aman dari lalu lintas, polusi, dan bahaya sosial; (c) anak-anak dapat melakukan kegiatan atau kontak langsung dengan alam; (d) anak-anak dapat mengakses tempat bermain dengan mudah" (http://www.courtyardhousing.org) dengan mudah.

Dalam pedoman ruang ramah anak ditekankan adanya dasar tradisi yang masih diyakini sebagai cirikhas, adat atau kebiasaan serta penanaman nilai luhur nantinya disebut dengan local wisdum. Local wisdom (kearifan setempat) sebagai gagasan-gagasan setempat (local) yang bersifat bijaksana, penuh kearifan, bernilai baik, yang tertanam dan diikuti oleh masyarakatnya (Kamus Inggris Indonesia John M. Echols dan Hassan Shadily). Kearifan lokal diartikan kebenaran yang mentradisi 
atau ajeg dalam suatu daerah, terbentuk sebagai keunggulan budaya masyarakat setempat maupun kondisi geografis dalam arti luas. Kearifan lokal tersebut merupakan produk budaya masa lalu secara terus-menerus dijadikan pegangan hidup (Gobyah, 2003). Nilai lokal yang terkandung di dalam bersifat universal dan menjadi sumber pengetahuan yang dinamis, berkembang dan diteruskan oleh populasinya dan terintegrasi dengan pemahaman terhadap alam dan budaya sekitar (Caroline NyamaiKisia (2010),

Istilah kearifan lokal di Yogyakarta dilandasi oleh budaya Jawa yang dikemas dalam simbol budaya: piwulang lan piweling (ajaran dan pengajaran). Dalam prinsip ini tujuan pendidikan dengan akal dan budi; disebutkan dengan kata bijak: 'mangasmingising budi', 'tepa selira' dan 'Memayu Hayuning Bawana'. Berangkat dari prinsip ini buku pedoman ruang ramah anak bersisi pertimbangan aksesibilitas, efektivitas, fleksibilitas, keamanan, kenyamanan, dan estetika. Substansi yang dikandung pengetahuan lokal menyatu dengan sistem kepercayaan, norma, dan budaya tradisi Yogyakarta yang tercipta suatu dan memupuk nilai-nilai norma, tata pergaulan sosial serta adat yang luhur yang relevan untuk pendidikan karakter anak

Ruang ramah anak terkait dengan kota layak anak dan sekolah layak anak, karena bertujuan untuk membangun tumbuh kembang anak dengan alami serta sesuai dengan prinsip bermain pada belajar anak.

\section{Menyusun Pedoman Ruang Ramah Anak}

Penyempurnaan buku pedoman ruang ramah anak untuk lembaga pendidikan anak usia dini ini diawali dengan Penelitian Pengembangan atau Research and Development (R\&D) untuk menghasilkan produk buku pedoman (Borg \& Gall, 1983). Penelitian ini melalui proses validasi produk berdasarkan siklus proses, terdiri: kajian tentang temuan penelitian produk pedoman yang akan dikembangkan, melakukan uji coba lapangan sesuai dengan latar dimana produk tersebut akan dipakai, dan melakukan revisi terhadap hasil uji lapangan. (Punaji, 2012, 215). Data penelitian berupa deskripsi tentang standar pelayanan minimal, deskripsi tentang bentuk dan susunan ruang kelas dalam satuan ngedung sekolah, prinsip media, peralatan bermain, serta analisis dampak lingkungan. Pemilihan lokasi penelitian di kabupaten Bantul ini 
berdasarakan informasi tentang dampak gempa terhadap perkembangan pendidikan terhambat.

Secara garis besar langkah penelitian ini adalah:

a. Pengisian ilustrasi yang memudahkan memahami isi buku pedoman.

b. Validasi oleh pakar dan pengguna maupun pemangku kepentingan: 1. Ahli Pendidikan Anak Usia Dini dari Fakultas Ilmu Pendidikan, program studi Pendidikan Anak Usia Dini, 2. Guru Pendidikan Anak Usia Dini, 3. Subag Sarana dan Prasana Diksluspora DIY.

c. Focus Group Discussion dengan pengguna dan pemangku kepentingan agar menemukan titik temu standar pelayanan minimal dan prinsip nilai kearifan lokal Yogyakarta.

d. Penyempurnaan buku panduan berdasar masukan dari focus group discussion.

e. Sosialisasi buku npedoman kepada 30 orang Guru PAUD di DI Yogyakarta.

Langkah-langkah penelitian secara multitahun

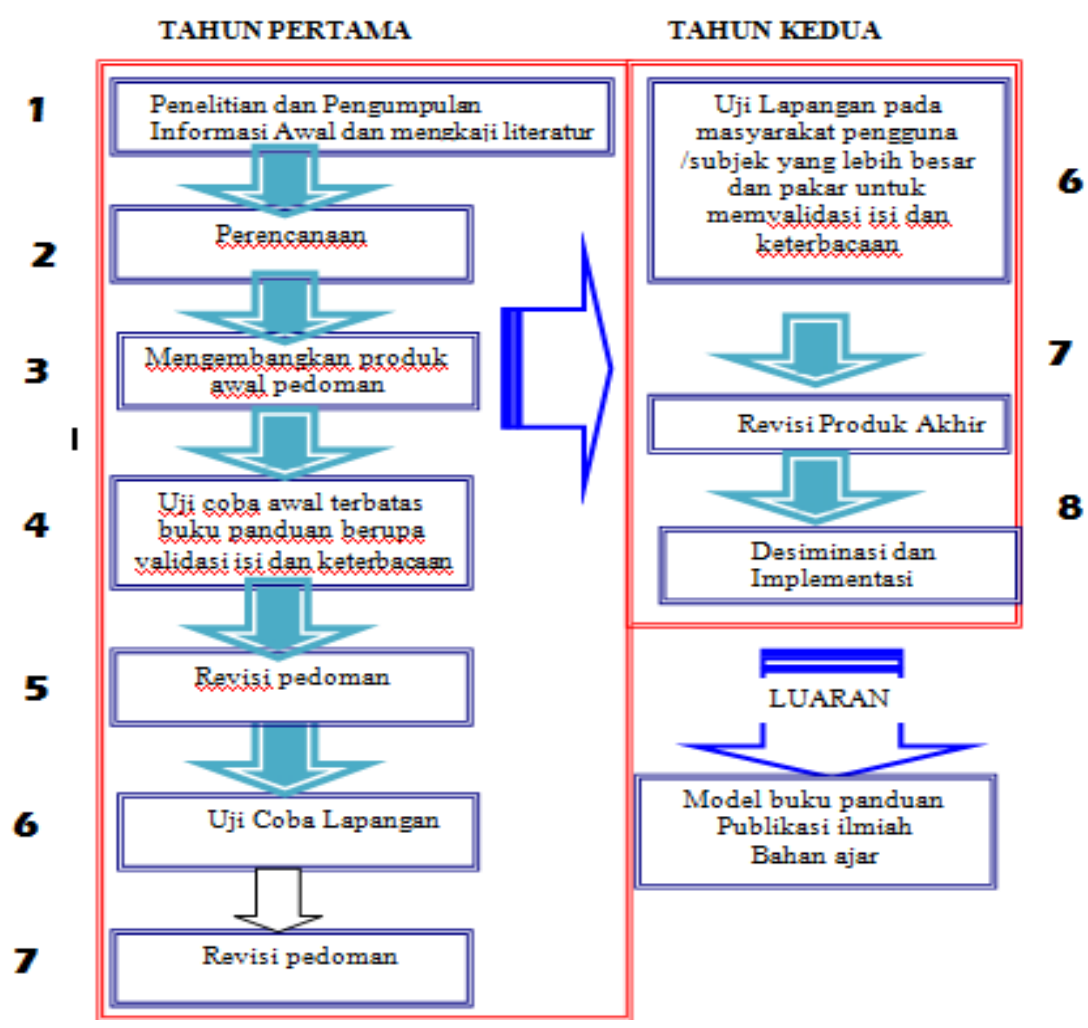


Gambar 1. Bagan alur tahapan penelitian multitahun

\section{Penelusuran Terhadap Kebutuhan Dasar untuk Menyusun Pedoman}

Berdasarkan penelusuran awal dengan purposive sampling terpilih 2 lembaga pendidikan anak usia dini sebagai sample penelitian, yaitu: PAUD IT Arroyan dan PAUD Bustanul Athfal Suren. Dari kedua sample yang terpilih berdasarkan karakteristik kearifan lokal baik dari segi pelaksanaan pembelajaran maupun bangunan yang masih mempertahankan bahan-bahan dari produk alami dan dari lingkungan sekitar. Di samping itu pemilihan sampel ini menunjukkan beberapa alat peraga, alat permainan dan media pembelajaran lebih menonjolkan tradisi dibandingkan dengan beberapa lembaga pendidikan anak usia dini di kota Yogyakarta.

Observasi terhadap lokasi dua lembaga penyelenggara PAUD bervariasi; secara garis besar digambarkan dalam tabel di bawah ini. Data observasi ini dicermati melalui Standar Pelayanan Minimal Manual Child Friendly School (UNICEF) ditemukan dasar kebuthan anak. Data tersebut didiskusikan lewat RGD dengan hasil Rang ramah anak dapat digambarkan sebagai berikut:

a. Maksud ruang ramah anak bagi masyarakat adalah ruang yang mampu memfasilitasi kegiatan bermain dan belajar dengan menimbulkan semangat belajar.

b. Ruang ramah anak dapat direncanakan kehadirannya (membangun sejak awal) maupun memodifikasi ruang dengan tata ruang yang ramah anak.

c. Ruang belajar dan bermain terpadu dengan pengelolaan self maintenance berdasarkan kebuthan dasarnya.

d. Ruang yang ada diharuskan sesuai dengan standar pelayanan minilal seperti yang sudah disusun oleh Dorektorat maupun Subdinas Pendidikan Nonformal, namun tetap disesuaikan dengan kondisi anak, misalnya jendela, pintu dan daun pintu yang tidak membahayakan sirkulasi gerak anak bermain maupun belajar.

e. Unsur kearifan lokal pada ruang (fisik) bertjuan mengyuatkan etika pergaulan melalui penataan ruang fisik utama belajar maupun ruang dukungan, seperti: WC (peturasan), fasilitas cuci tangan, sirkulasi ruang yang tidak saling kontra. 
f. Susunan perabot dan isinya mudah diakses oleh anak, serta memberikan suasana belajar secara nonformal (tidak disengaja merupakan alat belajar), seperti: tinggi rak, penataan mainan yang berat maupun ringan serta media yang mempunyai resiko rusak tinggi.

g. Ruang ramah anak berbasis kerafiran lokal yang dimaksudkan adalah ruang yang dekat dengan budaya anak di rumah, termasuk: pengisian media belajar yang mudah dan cepat dipahami anak, berdasarkan tingkat pemahaman alat sebagai benda untuk menyelsaikan permasalahan, maupun benda yang hanya berfungsi jika ada permasalahan, sampai dengan benda yang secara tidak langsung maupun langsung memberi kemudahan berpikir, berperasaan dan cinta akan kondisi sekitarnya.

h. Ruang ramah anak berbasis kearifan lokal ini diharapkan menempatkan media yang berbasis: adat, tradisi atau kebiasaan masyarakat, serta bernuansa budaya setempat. Seperti: media boneka yang bernuansa seni Klasik dan tradisi, wayang, kain jarik serta yang lain. Untuk seni Klasik diharapkan mempunyai dampak sikap apresiatif terhadap hasil budaya: seni dan cara berpikir. Wayang diharapkan dapat memberi perbandingan dengan hasil budaya luar, terutama penokohan dan pranata sosial nyang ada dalam cerota. Kain jarik yang bermotif batik akan memberi wawasan nilai-nilai edukasi bagi orang yang mengenakan serta meningkatkan njilai apresiatif terhadap kesenian tradisi.

Hasil penelitian di atas kemudian disusun menjadi buku pedoman dengan ketentuan organisasi percetakan maupun kebutuhan dasar pendidikan anak usia dini. Buku yang sudah tersusun ini dilakukan penilaian dari: (1) pengguna seperti pengelola PAUD, guru maupun masyarakat pemerhati PAUD. (2) para pakar di bidang: pendidikan anak usia dini. (3) Pakar bahasa agar menghasilkan keterbacaan teks. (4) pakar interior dan desain komunikasi visual ujntuk menguatkan tata ruang yang menyenangkan dan nyaman.

Secara global buku nyang tersusun dilakukan pengujian tersebut menghasilkan data sebagai berikut:

Tabel 1. Terpenuhinya persyaratan ruang PAUD yang ramah pendidikan anak 


\begin{tabular}{|c|c|c|c|c|}
\hline Bagian & Kriteria & Keterangan & Tambahan & $\begin{array}{r}\text { Memenuhi } \\
\text { syarat/tidak }\end{array}$ \\
\hline \multirow[t]{3}{*}{$\begin{array}{l}\text { Latar } \\
\text { Belakang }\end{array}$} & \multirow{2}{*}{$\begin{array}{l}\text { Isi sudah dapat } \\
\text { menunjukkan arah } \\
\text { dan maksud } \\
\text { pedoman ruang } \\
\text { ramah anak }\end{array}$} & $\begin{array}{l}\text { Bahasa } \\
\text { mohon } \\
\text { diseder- } \\
\text { hanakan }\end{array}$ & $\begin{array}{l}\text { Diperlukan penambahan } \\
\text { dalam hal prinsip ruang } \\
\text { anak dan dipadukan } \\
\text { dengan SPM yang ada }\end{array}$ & Memenuhi \\
\hline & & $\begin{array}{l}\text { Nilai } \\
\text { kearifan } \\
\text { lokal perlu } \\
\text { ditambahka } \\
\mathrm{n}\end{array}$ & Ditambahkan terintegrasi & $\begin{array}{l}\text { Sebagian } \\
\text { saja }\end{array}$ \\
\hline & $\begin{array}{l}\text { Tata susun sudah } \\
\text { memadai }\end{array}$ & - & - & Cukup baik \\
\hline $\begin{array}{l}\text { Dasar } \\
\text { Hukum }\end{array}$ & $\begin{array}{l}\text { Sudah } \\
\text { menunjuukkan } \\
\text { relevansi hukum } \\
\text { dengan rencana } \\
\text { pedoman } \\
\end{array}$ & Cukup & - & Memenuhi \\
\hline Ilustrasi & $\begin{array}{l}\text { Kurang ada petunjuk } \\
\text { teknis ukuran }\end{array}$ & Cukup & - & Memenuhi \\
\hline \multirow[t]{8}{*}{$\begin{array}{l}\text { Petunjuk } \\
\text { teknis }\end{array}$} & $\begin{array}{l}\text { Sudah } \\
\text { menunjuukkan ide } \\
\text { dan gagasan dan } \\
\text { mudah dipahami } \\
\text { namun lebih } \\
\text { disederhanakan }\end{array}$ & $\begin{array}{l}\text { Disederhan } \\
\text { akan }\end{array}$ & $\begin{array}{l}\text { Terlalu banyak atruran } \\
\text { main }\end{array}$ & Memenuhi \\
\hline & Furnitur & $\begin{array}{l}\text { Cukup } \\
\text { jelas }\end{array}$ & $\begin{array}{l}\text { Perlu tambahan meja } \\
\text { untuk pembelajaran yang } \\
\text { tanpa kursi (lesehan) }\end{array}$ & Memenuhi \\
\hline & Papan tulis & $\begin{array}{l}\text { Cukup } \\
\text { jelas }\end{array}$ & - & Memenuhi \\
\hline & $\begin{array}{l}\text { Zone Permainan } \\
\text { Drama }\end{array}$ & $\begin{array}{l}\text { Kurang } \\
\text { jelas }\end{array}$ & $\begin{array}{l}\text { Posisi ruang kelas banyak } \\
\text { yang hanya } \\
\text { memanfaatkan yang ada }\end{array}$ & \\
\hline & $\begin{array}{l}\text { Zone seni dan } \\
\text { kerajinan }\end{array}$ & $\begin{array}{l}\text { Cukup } \\
\text { jelas }\end{array}$ & Tentatif & Memenuhi \\
\hline & Kantor Administrasi & $\begin{array}{l}\text { Cukup } \\
\text { jelas }\end{array}$ & - & Memenuhi \\
\hline & Tata ruang & $\begin{array}{l}\text { Cukup } \\
\text { jelas }\end{array}$ & $\begin{array}{l}\text { Tentatif, menyesuaikan } \\
\text { dengan kondisi lembaga } \\
\text { yang ada }\end{array}$ & \\
\hline & Air yang aman & $\begin{array}{l}\text { Cukup } \\
\text { jelas }\end{array}$ & - & Memenuhi \\
\hline
\end{tabular}




\begin{tabular}{|c|c|c|c|}
\hline Toilets & $\begin{array}{l}\text { Cukup } \\
\text { jelas }\end{array}$ & $\begin{array}{l}\text { Diusahakan ada toilet } \\
\text { untuk pria dan wanita }\end{array}$ & Memenuhi \\
\hline $\begin{array}{l}\text { Cahaya, udara, } \\
\text { matahari, debu, silau, } \\
\text { refleksi, lembab, } \\
\text { kebisingan dan bau }\end{array}$ & $\begin{array}{l}\text { Cukup } \\
\text { jelas }\end{array}$ & $\begin{array}{l}\text { Kejelasan/terangnya } \\
\text { cahaya matahari, tidak } \\
\text { mengganggu pandangan }\end{array}$ & Memenuhi \\
\hline Warna & $\begin{array}{l}\text { Cukup } \\
\text { jelas }\end{array}$ & - & Memenuhi \\
\hline Daya listrik & $\begin{array}{l}\text { Cukup } \\
\text { jelas }\end{array}$ & - & $\begin{array}{l}\text { Menyesuai } \\
\text { kan kondisi } \\
\text { lembaga }\end{array}$ \\
\hline Peraturan kesehatan & $\begin{array}{l}\text { Cukup } \\
\text { jelas }\end{array}$ & - & Memenuhi \\
\hline $\begin{array}{l}\text { Perpustakaan dan } \\
\text { permainan }\end{array}$ & $\begin{array}{l}\text { Cukup } \\
\text { jelas }\end{array}$ & $\begin{array}{l}\text { Variatif, terdapat pada } \\
\text { setiap ruang atau khusus }\end{array}$ & Memenuhi \\
\hline Landscaping & $\begin{array}{l}\text { Kurang } \\
\text { jelas }\end{array}$ & $\begin{array}{l}\text { Karena tidak setiap } \\
\text { lembaga mempunyai } \\
\text { bangunan baru dan } \\
\text { Disesuaikan dengan } \\
\text { kondisi sekolah }\end{array}$ & Meneuhi \\
\hline
\end{tabular}

Hasil penilaian tahap pertama ini kemudian dilakjukan penyempurnaan dengan melakukan observasi lagi dan menambah referensi pustaka yang menyangkut prinsip ntata ruang dan pengelolaan sirkulasi ruang. Hasil ini merupakan penyimpulan dari Focus Group Discussion (FGD); dengan hasil sebagai berikut:

a. Latar Belakang (perlu diselipkan pengertian kearifan lokal dengan prinsip ke daerahan dan potensi lokal)

b. Dasar Hukum (jelas)

c. Petunjuk Teknis (beberapa gambar disesuaikan dengan kondisi lembaga)

\section{d. Ilustrasi (cukup jelas)}

Penilaian akhir dan FGD dengan 30 orang peserta menghasilkan buku pedoman yang telah mengamodasi kebutuhan dasar serta memperhatikan pola-pola pembelajaran yang dilakukan oleh guru. Hasil ini dikembangkan denganj penguatan referensi (studi pustaka). Beberapa pendapat dari pengelola PAUD dan Guru berharap pedoman ini ditindaklanjuti dengan mengirimkan buku kepada Kepala Dinas 
Pendidikan, Pemuda dan Olah Raga provinsi DIY serta Dirjen PAUD dan Pendidikan Nonformal.

\section{KESIMPULAN}

Berdasar hasil pelaksanaan kegiatan penelitian adalah informasi awal maupun akhir kajian literatur mengenai teori ruang ramah anak, teori ruang belajar, dan Informasi dari hasil observasi di lapangan yang sangat bermanfaat sebagai materi isi buku. Tahapan selanjutnya yakni melakukan Uji Coba Awal, revisi produk buku panduan, serta ujicoba lapangan. Produk pedoman yang telah direvisi dan diujicobakan kepada kelompok yang lebih besar menghasilkan data yang akurat. Data dikumpulkan dianalisis sesuai dengan tujuan khusus sehingga diperoleh data untuk melakukan revisi produk lebih lanjut. Berdasarkan data tersebut dilakukan evaluasi untuk diujicobakan lagi. Buku Pedoman yang disusun berdasarkan review dan FGD ini disempurnakan lagi dengan membandingkan Pedoman dan Standar Pelayanan Sarana dan Prasarana Direktorat Pendidikan Nonformal.

Akhirnya, selesainya penyusunan buku pedoman ruang ramah anak berbasis kearifan lokal mendapat bantuan dari beberapa pihak, untuk itu diucapkan kepada para pengelola PAUD, HIMAPUDI, Guru PAUD, Para Pakar di bidangnya yang telah mereview tulisan dan isinya, Pemerhati PAUD Yogyakarta serta Kepala Dinas Pendidikan, Pemuda dan Olah Raga Provinsi DIY beserta jajarannya yang telah memberikan dukungan dan kontrusi dalam penyusunan Buku Pedoman Ruang Ramah Anak Berbasis Kearifan Lokal. Tentau saja kekurangan selalu ada untuk itu para pembaca buku ini sudi meberikan uluran tangan menyempurnakan dengan mengiripkan kepada alamat imel di atas. 


\section{DAFTAR PUSTAKA}

Neufert, Ernst. 1996. Data Arsitek. Jakarta. Erlangga.

Punaji, Setyosari. 2012. Metode Penelitian Pendidikan. Jakarta: Kencana.

Handoko. 2004. Jurnal 2d3d. Vol.1No. 2.Universitas Pelita Harapan. Jakarta. 2011. "Tentang manual sekolah ramah anak". http://www.courtyardhousing.org, Diunduh, 22 April 2011 